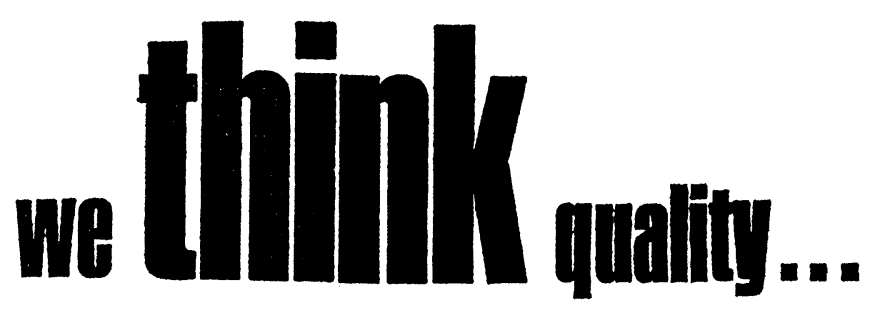

yet assure you of fast,

economical, accurate

work in all phases of

legal and financial printing.

Ask about annual

reports, letterheads,

brochures ...

they're all a

part of our

versatile printing

spectrum

Get that professional touch! call

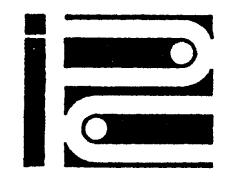

INTERNATIONAL PRINTING CO. 711 SOUTH 50th STREET = PHILADELPHIA - PENNGYLVANIA 19143 SAratoga 7-8711

\title{
Printers of the IJLL
}

